Etnográfica

Revista do Centro em Rede de Investigação em

Antropologia

vol. 13 (2) | 2009

Vol. $13(2)$

\title{
Graça Índias Cordeiro e Frédéric Vidal (orgs.), A Rua: Espaço, Tempo, Sociabilidade
}

\section{Paula Mota Santos}

\section{(2) OpenEdition}

\section{Journals}

Electronic version

URL: https://journals.openedition.org/etnografica/1179

DOI: 10.4000/etnografica. 1179

ISSN: 2182-2891

\section{Publisher}

Centro em Rede de Investigação em Antropologia

\section{Printed version}

Date of publication: 1 November 2009

Number of pages: $485-487$

ISSN: 0873-6561

\section{Electronic reference}

Paula Mota Santos, "Graça Índias Cordeiro e Frédéric Vidal (orgs.), A Rua: Espaço, Tempo, Sociabilidade", Etnográfica [Online], vol. 13 (2) | 2009, Online since 16 May 2012, connection on 12 February 2022 URL: http://journals.openedition.org/etnografica/1179; DOI: https://doi.org/10.4000/etnografica. 1179

\section{(c) (i) (9)}

Etnográfica is licensed under a Creative Commons Attribution-NonCommercial 4.0 International License. 
Graça Índias Cordeiro

e Frédéric Vidal (orgs.)

A RUA: ESPAÇO, TEMPO, SOCIABILIDADE

Lisboa, Livros Horizonte, 2008, 174 páginas.

Em finais de 2005, no âmbito de um projecto de investigação, realizou-se no ISCTE um colóquio intitulado "O lugar da rua: cidade, tempo, sociabilidade". Em 2008, com organização da investigadora principal e de outro investigador desse projecto, foi dada à estampa a presente obra, que recupera algo do título do colóquio e das suas participações.

O livro reúne contribuições sobre um mesmo tema: a rua. O tema escolhido é enganadoramente fácil. Como acontece com "cultura" (quem não sabe o que é cultura...?), a palavra "rua" (quem não sabe o que é a rua...?) encerra em si uma polissemia que é fruto do facto de não ser encarada unicamente (se é que de todo o é) como um elemento-tipo da estrutura urbana. As polissemias são desafios interessantes: o investigador não só tem de dar conta dessa riqueza do real evitando focalizar uma única componente, como terá de lidar com o facto de que as realidades polissémicas são frequentemente contraditórias em si mesmas e são marcadas por fluxos e refluxos e ângulos de visão múltiplos em função de agenciamentos situados, quer no tempo, quer no espaço. Da dificuldade da definição da unidade de análise social "rua" está a organização do livro bem ciente, quando afirma tomar a rua como problema a identificar e não como unidade definida a priori (p. 9). A "rua” como espaço social poderá ser definida como tudo aquilo que está fora de/da "casa". Mas as fronteiras entre um espaço social e o outro são, mais que fluidas, porosas. Facilmente estes espaços (o exterior/a rua; o interior/a casa) se colocam nas coordenadas um do outro. As contribuições deste livro são todas olhares que se focam no "lá fora" e, vindas de saberes diferentes, produzem um volume que fornece a quem o ler possibilidade certa de enriquecimento intelectual, quer seja gente da academia quer gente com um interesse curioso por alguns do terrenos retratados e analisados, neste caso, Lisboa, pois se há coisa que sobressai neste volume é o facto de a maioria desses terrenos (sete de entre os nove apresentados) serem nesta cidade, o que faz com que este livro seja (também) um livro sobre Lisboa.

Dos treze autores listados, seis são antropólogos, quatro são historiadores, dois são sociólogos e um é arquitecto. E, no entanto, corre-se o livro sentindo que se está sempre no mesmo universo intelectual, numa quadratura que, sendo constituída por multiplicidades, não deixa nunca de se construir em teia de uma mesma arquitectura de curiosidade e busca intelectual de cunho antropologizante. No entanto, o livro não resulta nunca em algo próximo de um somatório de textos que se poderiam sentir até avulsos, porque, mais do que a "rua" que partilham (que é sempre tão diferente de um texto para o outro - riqueza máxima do livro), há uma eficaz "Introdução" que vai tecendo malhas de ligação por entre os textos do livro.

Falar de "rua" implica falar de cidade. Agier fala de uma cidade profundamente actual: os campos de refugiados. Abre pois o livro com um texto que pode parecer paradoxal, pois fala de cidade por relação a algo (aglomerações de indivíduos deslocados e despojados não só de bens mas, principalmente, de direitos, de entre os quais o menor não será certamente o da liberdade) que parece ser a objectificação da negação do "facto de civilização" (p. 17) que a cidade se supõe ser. Negando o seu interesse em "olhar os campos em função [...] da forma de cidade conhecida como organização do 
espaço" (p. 21), Agier espicaça-nos a fazer uma antropologia da mundialização que não se fique pelo abstracto dos fluxos "que parecem não ter uma realidade empírica" (p. 20). Sabendo-se que estes campos são mecanismos de controlo de sujeitos e sabendo-se que há realidades aqui na "nossa" Europa que são isso mesmo, não pode o pensamento não se lembrar de Foucault e da sua historiação dos modelos de vigilância e punição que fomos construindo; desejamos que Agier tivesse tentado elaborar para além de Foucault, mas com Foucault, o que este não chegou a conhecer no grau que hoje conhecemos e que constitui tema da contribuição de Agier.

Da aparente "des-formalidade" da rua dos campos de deslocados passo para a absoluta formalidade da rua da cidade europeia do século XIX. Aqui, duas contribuições de historiadores, Gribaudi e Vidal, e duas cidades, Paris e Lisboa. O primeiro traça a cidade não dominante, a cidade que a nova modernidade dos boulevards haussmanianos foi eclipsando, antes de a fazer efectivamente desaparecer. A Paris intersticial que Gribaudi retira das brumas do esquecimento histórico é marcada pelo desejo de salubridade, quer higiénica quer social, que guiou a acção regulatória da cidade dominante (burguesa/capitalista) sobre estes espaços profundamente vitais (a reconstituição histórica das actividades profissionais de uma só rua mostra-o). A Lisboa de Vidal é-nos mostrada também em mutação: uma cidade que vai sendo regularizada (que se auto-regulariza?), como nos mostra a análise (brilhante na sua capacidade de ir para além do puramente factual, alcançando o sentido simbólico e vivenciado do espaço) de algo aparentemente banal: a organização da posta diária. A história que nos arranca do esquecimento a humanidade desaparecida é boa história, e a Paris e a Lisboa que estes historiadores nos fornecem são colocadas perante os nossos olhos profundamente vivas, lembrando o trabalho do geógrafo A. Pred com a Estocolmo do século XIX. Como Pred, o que Gribaudi e Vidal nos mostram é como a lógica do capitalismo inicial vai moldando as cidades, fazendo emergir essa regulamentação e ordenação funcional dos espaços e gentes, requisito central do sistema que se instala.

Regulamentação e re-organização urbana estão também nos textos de Nunes e Baptista, de Farina e de Pujadas. Se no primeiro ainda encontramos alguma da Lisboa da industrialização inicial (construção por especuladores imobiliários do Bairro do Rego), com o bairro de Olivais Sul entramos numa realidade urbana metropolitana que tem já vasos comunicantes com a apresentada por Farina (habitação Matriz H em Chelas). Pujadas aborda questões que se inserem num universo metropolitano de alta modernidade, em que os chamados centros históricos se constituem foco de atenção/intervenção por parte do poder público. Nunes e Baptista, embora tenham uma abordagem muito morfológica da rua, permitem-nos ver como centro e periferia (enquanto conceitos simbólicos e não geométricos) se vão constituindo por relação um ao outro. Farina remete-nos para uma abordagem mais ecológica e um olhar mais atento ao detalhe arquitectónico, ao tentar decifrar as apropriações e "des-apropriações" das estruturas idealizadas pelos arquitectos naquilo que é uma unidade de habitação social. Do que é referido por relação a Olivais Sul e à Matriz H, pode claramente ver-se como as vizinhanças, enquanto conjunto de relações que se constroem ao longo do tempo, são algo não potenciado por estes conjuntos habitacionais, que continuam a ser uma cidade "pouco cidade", onde predomina a função de dormitório, limitando os tempos de socialização efectiva na densificação e construção de uma tessitura vicinal viva. Tessitura vicinal viva é aquilo que se encontra nos centros históricos, e Pujadas 
mostra-nos no Raval e na Madragoa como estas populações (normalmente nas margens da cartografia social porque envelhecidas, com rendimentos económicos muito baixos e porque etnicamente diversas devido a migrações cada vez mais marcantes) são deslocadas pelas intervenções urbanísticas sobre (e para a apropriação da) urbe patrimonializada, provocando assim "graus de fractura social e défices de coesão" (p. 152). O texto de Sieber, que surge após o de Agier, fala também da cidade da alta modernidade que Pujadas refere, mas a intersecção destes dois textos vem fundamentalmente da emergência da cidade-região e da sua imersão em redes globalizantes (a intervenção no Raval é relacionada com os Jogos Olímpicos de Barcelona em 1992 e Sieber aborda as ruas do recinto da exposição mundial de Lisboa de 1998 contrapondo-as à "sua" rua de Alfama). Particularmente interessante é a reflexão que Sieber faz sobre o carácter oposto do sentido da "rua" enquanto local de vivência no universo norte-americano e no europeu (Sul da Europa), sendo que o carácter público das vivências realizadas neste último não tem a conotação de marginalidade que tem no primeiro. A rua como exterioridade, como espaço simbólico construído pelas vivências que aí se desenrolam é o que nos mostra o texto de Durão, que nos dá uma etnografia cuidada de três tipos de policiamento de uma esquadra na Lisboa de hoje, interligando-os com exercícios de poder diferentes e diferenciados, desvendando uma tessitura complexa sob algo de aparência linear.

Vivência da/na rua une as contribuições de Cachado e de Ferreira. Separa-as o tempo em estudo, a proximidade/distância (trabalho de campo etnográfico/Cachado; documento histórico/Ferreira) e a escala (bairro da Quinta da Vitória; o país). Mas em ambas temos a rua como palco de celebrações (comunidade hindu; liberais e miguelistas) em que o sentido público e publicitado dessas celebrações serve como factor de ajustamento de relações de poder. Termina o livro com as palavras do comentário final de Y. Lequin no colóquio que originou este volume. Devido à nota marcadamente oral do texto, têm o valor de testemunho histórico de um momento.

Além da riqueza e qualidade das abordagens presentes, há a referir o facto de esta ser a concretização editorial de um encontro científico, alargando assim os públicos do mesmo e cumprindo com uma obrigação fundamental da academia: a divulgação do saber que produz. Entende-se assim que este é um livro que marca o panorama português das publicações sobre estudos urbanos, sendo leitura útil aos que se interessam por esta temática.

\section{Paula Mota Santos}

Universidade Fernando Pessoa 